\title{
Subjetividade na Renovação Carismática Católica: Mecanismos de Funcionamento e de sua Produção
}

\author{
Silvio José Benelli \\ Universidade Estadual Paulista Júlio de Mesquita \\ Filho SP, Brasil.
}

\author{
Samuel Iauany Martins Silva \\ Universidade Estadual Paulista Júlio de Mesquita \\ Filho, SP, Brasil.
}

Resumo: Este texto trata de discorrer sobre uma pesquisa acerca da Renovação Carismática Católica (RCC) a partir de uma revisão bibliográfica e de análise documental, desenvolvendo uma Análise Institucional (AI) "no papel” e tendo como pilar teórico, trabalhos institucionalistas desenvolvidos no campo da Psicologia social sobre o tema dos movimentos religiosos no contexto da Igreja Católica. A RCC é um movimento religioso que surgiu nos Estados Unidos da América em 1967 e se expandiu amplamente, marcando forte presença no Brasil. O principal foco deste artigo foram os mecanismos de produção de subjetividade que esse movimento emprega: pensamos seus efeitos em termos de saber/poder sobre a vida de seus participantes e percebemos que existe um padrão normalizador veiculado por seu discurso oficial, que é intensamente difundido por meio da televisão, da Internet, de livros e eventos que envolvem grandes multidões, difundindo e promovendo uma subjetividade serializada. Além disso, entendemos que seus mecanismos de ação se aproximam dos movimentos de caráter totalitário. Palavras-chave: Psicologia Social, Análise Institucional, Subjetividade, Singularidade.

\section{Subjectivity in the Catholic Charismatic Renovation Movement: Mechanisms of Operation and their Production}

\begin{abstract}
This article discusses a research on the Catholic Charismatic Renewal (CCR) movement from a bibliographic review and a document analysis, developing an Institutional Analysis "on the paper", having as a theoretical guide the works in Social Psychology about religious movements in the Catholic Church. The CCR is a religious movement born in the United States of America in 1967 that expanded largely, with a strong presence in Brazil. The main focus of this article was on the production of subjectivity mechanisms that are used by this movement: we considered their effects in terms of the knowledge/power they have on the life of their members and of the normalization pattern that is propagated by their official speech, widely broadcasted on television, internet, books and events involving lots of people, diffusing and creating a serialized subjectivity. Furthermore, we understand that their mechanisms of action are close to those of movements with totalitarian character.
\end{abstract}

Keywords: Social Psychology, Institutional Analisys, Subjectivity, Singularity. 


\title{
La Subjetividad en la Renovación Carismática Católica: Mecanismos de Funcionamiento y su Producción
}

\begin{abstract}
Resumen: Realizamos una investigación acerca de la Renovación Carismática Católica (RCC) a partir de una revisión bibliográfica y un análisis documental, desarrollando un análisis institucional (IA) "en papel” y teniendo como pilar teórico trabajos institucionalistas hecho en el campo de la psicología social con tema de los movimientos religiosos en el contexto de la Iglesia Católica. La RCC es un movimiento religioso que surgió en los Estados Unidos de América en 1967 y se extendió considerablemente, marcando una fuerte presencia en Brasil. Este artículo se enfocó en los mecanismos de producción de subjetividad que ese movimiento emplea: pensamos sus efectos en términos de saber/poder sobre la vida de sus participantes y del patrón normalizador vehiculado por su discurso oficial, que es intensamente difundido por televisión, internet, libros y eventos que abarcan multitudes, difundido y promoviendo una subjetividad en serie.

Palabras clave: Psicologia Social, Analisis Intitucional, Renovacíon Carismática Católica, Subjetividad, Singuralidad.
\end{abstract}

Este artigo abarca discussões teóricas acerca da Renovação Carismática Católica (RCC), com base na Psicologia Social e Análise Institucional (AI), tematizando o campo religioso brasileiro. A religião é algo intensamente difundido e enraizado na cultura e, no Brasil, de modo particular, está presente e atuante desde a colonização até a atualidade. O catolicismo está profundamente impregnado na construção e formação social brasileira. Dessa forma, é de grande importância para a ciência e para a sociedade que se produzam discussões sobre o assunto. Verificamos que são numerosas as pesquisas e publicações em Psicologia que tratam da religião, mas não são muitos os estudos que se baseiam na $\mathrm{AI}$ e que tematizam os processos de produção de subjetividade nesse contexto (Benelli, 2010a; 2010b; 2010c). A pesquisa que embasa este artigo foi influenciada pela obra de Benelli (2006) e de Benelli e Costa-Rosa (2006), autores que utilizam a AI para estudar a produção de subjetividade no contexto religioso católico, enfocando, sobretudo, a questão da formação do clero católico em seus estudos.

A RCC é um movimento religioso de grande alcance no Brasil, e possui uma organização institucional complexa e interessante. Os indivíduos são "resgatados" do mundo para dentro do movimento, no qual assumem papéis de leigos/servos/formadores. Segundo Benelli (2006) e Benelli e Costa-Rosa (2006), as instituições (re)produzem subjetividade, e esta pode ser analisada mediante discursos e práticas.
Assim como Benelli (2006; 2010a; 2010b; 2010c) considera o seminário católico um dispositivo social de produção de subjetividade, pensamos ser possível estudar e analisar a RCC como uma instituição e um dispositivo, pois ela possui uma consistência discursiva e doutrinária específica, modos de funcionamento próprio, que se (re)produzem nas práticas cotidianas dos seus integrantes.

Analisar criticamente os mecanismos de produção de subjetividade em funcionamento em uma instituição que influencia um número considerável de pessoas torna possível também a verificação dos efeitos de poder na vida de seus participantes. Essa análise permite-nos pensar e lançar discussões sobre processos de fanatização religiosa, bem como sobre a elaboração de resistências do indivíduo quanto ao poder que o alcança de modo capilar e normalizador. Acreditamos que, orientados pelo estudo dessas teorias relativas à produção de subjetividade e à AI, verificar isso se torna possível. Para entender os mecanismos produtores de subjetividade da RCC, fizemos um levantamento de documentos desse movimento, tais como: apostilas de formação doutrinária, material utilizado na formação de pregadores (pessoas que levam à frente o ideal do grupo), projetos pedagógicos, documentos de planejamento estratégico relativos a eventos e voltados para a formação de seguidores. Buscamos também livros de autores e pesquisadores que escreveram sobre tal movimento. 
Discutimos essa literatura a partir da perspectiva da Análise Institucional, demonstrando os mecanismos utilizados pelos dirigentes da RCC na construção de discursos e de práticas modeladoras de subjetividade.

Inicialmente faremos algumas reflexões acerca dos elementos da AI que utilizamos, para depois falarmos do conceito de subjetividade, com a especificidade que lhe demos nesse trabalho. Debateremos também alguns aspectos da religiosidade carismática, da sua prática e modo de funcionamento institucional, bem como relacionaremos as características desse grupo com os movimentos religiosos totalitários analisados por Benelli e Costa-Rosa (2006).

\section{A Análise Institucional como perspectiva teórica e analítica}

Optamos pela AI como abordagem teórica justamente por que ela nos proporciona uma análise do elo que se pode estabelecer entre o funcionamento de uma instituição - um movimento religioso específico, situado no contexto eclesial católico - na sociedade atual, e os jogos e mecanismos de poder e saber, bem como os efeitos produzidos em termos de produção de subjetividade. Baremblitt (1994, p. 13) explica que o “Movimento Institucionalista" é mais amplo que a AI propriamente dita, apresentando os principais ideais comuns aos vários agrupamentos que se inserem nesse vasto movimento. Para Baremblitt (1994, p. 15), é característico de nossa sociedade produzir um saber científico sobre si mesma, sobre seu próprio modo de funcionamento, denominando os profissionais, os intelectuais, os especialistas no estudo da sociedade como sendo os "experts", que estão geralmente a serviço dos estabelecimentos sociais que detém maior poder, controle e hegemonia social. Dessa forma, o saber das pessoas sobre si fica relegado ao segundo plano, inclusive sendo passível de desqualificação frente ao saber tido como sendo científico e superior sobre elas mesmas. Tais pessoas dependem, portanto, quase que totalmente dos organismos de Estado, empresariais, de instituições que "sabem" sobre elas, dentre elas, podemos situar a universidade e também a própria instituição social da religião. Todos esses organismos geram serviços, produzem bens, administram territórios e utilizam de um tipo de força. Essa nem sempre é física, pode ser também persuasiva. As decisões tomadas por tais grupos, segundo Baremblitt (1994, p. 29), privilegiam as classes dominantes. Mas essa afirmação não é feita de modo generalizador, como se todos os representantes dessas instituições fizessem isso com intencionalidade premedita; o que costuma acontecer é que seu próprio saber sobre os modos de funcionamento "do social" já está produzido segundo mecanismos que privilegiam os interesses dominantes.

Existe um conceito da AI que se chama "demanda", que indica as exigências que se originam devido às necessidades básicas de comunidades e coletividades. Para o institucionalismo, não existem demandas naturais e espontâneas, mas se afirma que toda necessidade é produzida e as demandas são moduladas socialmente. Dessa forma, as pessoas são levadas a crer que pedem o que precisam, enquanto na verdade elas sentem que precisam daquilo que os especialistas oferecem, postulando que é disso que precisam. Baremblitt (1994, p. 27) caracteriza a sociedade como um tecido de instituições. Uma instituição consiste, sobretudo, numa lógica. As instituições podem ser leis, pautas, normas e regularidades de comportamentos. Além disso, esses valores podem ser formalizados por escrito ou transmitidos verbalmente. Essa lógica da instituição propõe modalidades de conduta e estabelece mecanismos de vigilância sobre os comportamentos dos seus componentes, afirmando o que deve e o que não deve ser, o que é indiferente etc. Ou seja, prescreve um padrão normalizador. Sobre a instituição da religião, por exemplo, Baremblitt (1994, p. 29) comenta que ela regula as relações dos homens com a divindade. Nela existem uma série de comportamentos indicados e outros contraindicados. Para realizar seus desígnios, as instituições precisam se materializar, e fazem isso por meio das organizações, que podem ser grandes ou pequenas, que podem ser compostas por meio de estabelecimentos (como os Grupos de Oração da RCC). Os estabelecimentos utilizam dispositivos técnicos que se denominam equipamentos. Todo esse complexo só se torna possível pela existência de agentes que enunciam discursos e realizam práticas as quais criam, instituem e transformam a realidade. Todos esses elementos: instituição, organização, estabelecimento, equipamento adquirem dinamismo através dos agentes (atores institucionais), os sujeitos que são os suportes e protagonistas da atividade coletiva microfísica responsável pela existência concreta da instituição. Os atores institucionais protagonizam práticas sociais que podem ser verbais, não verbais, discursivas, teóricas ou técnicas, políticas e éticas. 
Baremblitt (1994, p. 32) postula ainda dois outros conceitos importantes da AI: chama de "instituinte" as forças de modificação e transformação criativa e inovadora de uma instituição. O "instituído" é o resultado do processo de criação instituinte, depois do processo de institucionalização se realizar e tende sempre a ser uma força conservadora, mantedora da ordem vigente. Um é resultado, o outro é processo. O instituído é estático, aparecendo como normas e leis que regem comportamentos. Entretanto, como o funcionamento social está em constante mutação, o instituído deve dar lugar a novos instituídos que promovam transformações. Essa força deve estar permanentemente aberta à "potência instituinte". Portanto, as instituições devem manter a relação entre essas duas forças sempre elástica, flexível. Também é preciso admitir - sem ingenuidade - que as instituições não progridem sempre para o melhor, também pode haver processos involutivos, regressivos, além de paralisia e de estase. Quando se sobrepõem as relações em nível conservador e a favor da reprodução, a AI denomina esse processo de "atravessamento"; quando há uma interpenetração das instituições em nível do instituinte, denomina-se "transversalidade".

Lourau (1996) afirma que em toda "norma universal" se trata sempre de uma instituição. Toda forma social visível, dotada de uma organização jurídica ou material pode ser considerada como uma instituição. $\mathrm{O}$ conceito de instituição assume três momentos distintos: a universalidade, a particularidade e a singularidade. Primeiramente, no momento da universalidade é que a instituição, como conceito, é plenamente verdadeira, mas no plano geral, abstrato. Isso se verifica no caso de uma verdade ou uma norma social. No plano da particularidade, a universalidade é negada. "Toda verdade geral deixa de ser tal plenamente desde que se encarna" (Lourau, 1996, p. 10). Quando uma norma universal se aplica a condições particulares dos indivíduos heterogêneos da sociedade, ela deixa de ser plenamente verdadeira, ela se modifica. Portanto, Lourau (1996) afirma que não se deve confundir universalidade com totalidade. A norma universal não se encarna diretamente no indivíduo, mas passa antes por formas sociais singulares e por modificações adaptativas. "O momento da singularidade é o momento da unidade negativa, resultante da ação da negatividade sobre a unidade positiva da norma universal" (Lourau, 1996, p. 10).

Toda forma social possui um caráter específico, criado por sua finalidade primeira, oficial, que consi- derada sozinha tem o nome de função. Lourau (1996) afirma que essa unidade funcional das organizações sociais é negativa. Na realidade, a finalidade primeira da instituição está ligada a outras finalidades, criadas pela influência e relação com outras organizações. Uma escola, por exemplo, tem a finalidade de ensinar a ler e a escrever, de ensinar as matérias básicas para as crianças. Entretanto, ela não produz só isso, ela produz comportamentos, ensina obediência, bons modos, ensina moral, disciplina os corpos, dobra a vontade política das crianças etc. Esse elemento teórico nos permite o olhar sobre os atravessamentos e as possíveis transversalidades de características de outras instituições na RCC. Lourau (1996) afirma que a AI é necessária porque as organizações sociais não podem ser totalizadas como um sistema positivo que basta se desmontar para se analisar, pois considera que as instituições são

Totalidades parciais, e por este aspecto, duplamente trabalhadas pela negatividade. Sendo totalidades, apresentam a negatividade formal que se liga a todo fato social positivo, na medida em que toda positividade simples e imediata contém já sua própria negação. Sendo parciais, isto é, envolvidas pelo conjunto das formas de organização que constituem o sistema social, podem entrar em oposição absoluta com o sistema (Lourau, 1996, p. 16).

A AI permite, portanto, que possamos problematizar a característica negativa da constituição das instituições, e tentar percebermos as lacunas, encontrarmos problemas onde só se veem soluções. Podemos, dessa forma, construir a consciência sobre o não dito institucional.

Colocadas essas considerações conceituais, é preciso esclarecer que há dois modos de se fazer $\mathrm{AI}$ : a análise "no papel" e a socioanálise. A primeira modalidade consiste, por exemplo, na AI de um movimento religioso católico, como o que realizamos. Trata-se de considerar a religião católica como instituição, problematizando a própria constituição do seu campo como um conjunto de saberes e práticas, relacionados a um contexto amplo, de ordem ideológica, espiritual, política, social e técnica. Não há demanda da RCC por um trabalho de análise, mas podemos tomar uma massa documental e bibliográfica que nos permitam tomá-la como estabelecimento institucional e analisar seus processos de funcionamento e modos de produção de 
subjetividade. A segunda possibilidade seria a AI $n a$ RCC, a partir de uma demanda de intervenção endereçada a um analista institucional, chamada de socioanálise. Por meio dela seria possível atuar e intervir no interior de estabelecimentos institucionais, participando de seus diversos processos microssociais e micropolíticos, junto aos seus membros integrantes.

\section{Explicitando o tema da produção da subjetividade}

Antes de discorrermos especificamente sobre a RCC, vale fazer um recorte sobre o conceito próprio de "subjetividade" e quais as vias e pontos de partida que tomamos ao tratar dele, nessa investigação. Ao discorrermos sobre subjetividade, falamos de um ponto de vista específico: partimos de uma Psicologia social crítica, embasada principalmente nas ideias de Foucault e Guattari, passando por Benelli (2006), que se apropriou de conceitos de ambos em seus trabalhos. Benelli (2006) afirma que "toda produção institucional pode ser entendida como produção de subjetividade, de sujeitos produzidos a partir de uma subjetividade serializada ou singularizada" (Benelli, 2006, p. 65). Portanto, se o que fazemos aqui é um trabalho de AI, consequentemente fazemos também uma investigação sobre a produção de subjetividade. Mas, por que analisar uma instituição, seus discursos e suas práticas, nos permite estudar algo como a subjetividade dos indivíduos que a compõem? É que partimos da premissa foucaultiana de que o campo da prática de uma instituição é um campo político, produtor de verdades, por meio do jogo entre poder/saber (os quais são conectados e se produzem reciprocamente). Vale ressaltar que, ao falarmos de subjetividade, não falamos de uma dicotomia entre corpo/mente, interior/exterior, dentro/fora, mas falamos do sujeito encarnado em um corpo, corpo este que será justamente o alvo das práticas sociais produtoras de subjetividades: "Mas o corpo também está diretamente mergulhado num campo político; as relações de poder têm alcance imediato sobre ele; elas o investem, o marcam, o dirigem, o supliciam, sujeitam-no a trabalhos, obrigam-no a cerimônias, exigem-lhe sinais" (Foucault, 1999, p. 30).

Por meio dessa ação sobre o corpo, portanto, a subjetividade se produz. O modo pelo qual nos tornamos sujeitos, segundo este pensamento, é denominado de "subjetivação". De acordo com as análises de Benelli (2006), ao se apropriar do pensamento de Foucault, verificamos que o sujeito e sua constituição são inseparáveis das "tecnologias de si" (os modos pelos quais é possível que o sujeito se relacione consigo). Portanto, é possível observar que o sujeito se constitui e se conhece por meio de certas práticas, que o fazem pensar, analisar e transformar seu corpo, sua alma, seu próprio eu.

A subjetividade, o sujeito, para Foucault, envolve um processo de subjetivação, visto que, segundo suas próprias palavras, não existe constituição do sujeito moral sem modos de subjetivação (Foucault, 1984, p. 28), ou seja, toda experiência que concretiza uma subjetividade envolve modos historicamente peculiares de se fazer a experiência de si (subjetivação) (Cardoso Junior, 2005, p. 344).

Portanto, chegamos a um ponto de afirmar que "toda subjetividade expressa algo de impessoal" (Cardoso Junior, 2005, p. 344). Uma forma de análise dessa questão muito utilizada por Benelli (2006) e por Benelli e Costa-Rosa (2006) é a distinção conceitual de modalidades da subjetividade a partir de dois submodos: a singularizada e a serializada. Vamos esmiuçar melhor esses conceitos e a questão da subjetividade, partindo das ideias de Guattari e Rolnik (1996).

Guattari (1996) elabora o conceito de subjetividade maquínica, ou seja, fabricada, moldada e consumida, perspectiva que também adotamos em nossa pesquisa. O filósofo faz a análise da subjetividade tomando como referência o sistema capitalista, sistema global, mas principalmente ocidental. Ao contrário de um sistema tradicional onde a subjetividade é produzida territorialmente, no contexto restrito de uma etnia ou uma casa, no sistema capitalista ela é fabricada de modo industrial e internacional, tendo alcance global. Poderíamos dizer que se implantam representações nas pessoas, e mais do que isso, as pessoas são produzidas de certo modo, têm sua subjetividade modelada. A questão da produção de subjetividade sai do âmbito das superestruturas, e passa a ser creditada também às forças produtivas de "ponta" (tecnológicas, industriais, midiáticas globais etc.). O autor afirma que os indivíduos responsáveis pela produção capitalista entenderam muito bem que, para se manter a hegemonia de mercado, mais importante que qualquer outra coisa, é necessário produzir subjetividade. As marcas deixadas no sujeito 
não se dão apenas no nível ideológico, mas alcançam seus modos de ver o mundo, de pensar, de sentir as coisas, de viver as experiências. Tudo o que nos chega por meio da linguagem, das imagens, da família, dos objetos de consumo são conexões com as grandes máquinas de produção e controle social e "as instâncias psíquicas que definem a maneira de perceber o mundo" (Guattari, 1996, p. 27). Explicitando melhor a relação entre produção de subjetividade e a produção econômica, Guattari (1996) vai elucidar que tal produção não é apenas a criação de um poder com a finalidade do controle social, mas "a produção de subjetividade constitui matéria-prima de toda e qualquer produção" (Guattari, 1996, p. 28).

O conceito marxista de ideologia não nos permite entender a questão subjetiva de modo cabal e exaustivo. Isto porque, segundo o autor, a ideologia fica na esfera da representação, enquanto a subjetivação é da esfera da "modelização" (Guattari, 1996, p. 28), e abarca os modos do sujeito de relação consigo, de viver e sentir suas experiências, ou os modos de ser, pensar, sentir e agir. Segundo tal linha de pensamento, não é possível entender os grandes fenômenos sociais, sem levar em conta toda a produção de subjetividade necessária naquele meio social, para que eles se reproduzam efetivamente. Se pensarmos em uma revolução ou em uma revolta política, por exemplo, não é possível entendê-la sem levar em conta as subjetividades que emergem nesse meio, subjetividades que não admitem mais se submeterem a ordem vigente.

Em relação a todas as teorias e práticas que se interessam pelo discurso do próximo, como a Psicologia, a pedagogia etc., existe um impasse micropolítico importante: ou elas se alinham e reproduzem essa criação de modelos, que, para o filósofo, sufocam os processos de singularização, ou elas se contrapõem a eles, na medida do possível, de acordo com os agenciamentos que conseguirem organizar. Portanto - e esse é um fator importante para a prática científica na área de humanas -, para esse tipo de ciência não existe neutralidade em relação ao objeto. Para Guattari (1996), os profissionais psi ou universitários desse campo, que optaram por serem somente canais de transmissão de conhecimento, seriam reacionários em sua escolha, na medida em que mantém a ordem vigente, a ordem do instituído. Portanto, parece plausível afirmar que a postura ética de um profissional das ciências humanas é a "atividade", sendo participativo e capaz de se misturar com seu objeto, em um processo de movimentação das subjetividades e criação permanente de realidade social e subjetiva.

Ao tratar do sujeito, Guattari (1996, p. 31) utiliza o conceito de agenciamento coletivo de enunciação, que não se refere nem a uma entidade individuada nem a uma entidade social predeterminada. A subjetividade seria, então, produzida por esses agenciamentos coletivos de enunciação. Os processos da produção de sentidos não são formados interiormente, intrapsiquicamente, nem apenas exteriormente, por agentes grupais e/ou institucional. Esse processo é produzido duplamente, e pode ter tanto natureza extrapessoal, como os sistemas econômicos, a mídia etc., quanto infrapessoal, como sistemas de percepção, sistemas fisiológicos, sistemas de produção de ideias etc. Nota-se aqui a transformação do conceito de sujeito e seu descolamento de noções mecanicistas e naturalistas. O filósofo também contribui com outra distinção, muito útil para uma Psicologia crítica: a do conceito de subjetividade com o conceito de individualidade. Esses dois termos estão extremamente associados no senso comum: o que é subjetivo significa individual. Entretanto, para o filósofo, é necessário separá-los. O indivíduo "é resultado de uma produção de massa" (Guattari, 1996, p. 31), ele é modelado, taxado, normatizado, portanto, serializado. Enquanto que o conceito de subjetividade não pode se centrar no plano individual. "Uma coisa é a individuação do corpo. Outra é a multiplicidade dos agenciamentos de subjetivação: a subjetividade é essencialmente fabricada e modelada no registro do social" (Guattari, 1996, p. 31). Ele cita como exemplo o ato de dirigir. Ele é automático, não é o indivíduo, não é o cogito cartesiano que dirige, pois o movimento flui de modo próprio, para além do plano meramente racional. Entretanto, quando se precisa agir, nesse caso, em uma situação de perigo ou de atenção, um $e u$ intervém, um indivíduo intervém, uma ideia de si, de corpo inteiro.

Guattari afirma, também que, quando falamos da produção de linguagem, de desejo, por exemplo, não é apenas o ser individual do homem que participa dessa produção, mas toda uma multiplicidade de agenciamentos de subjetivação. A subjetividade, portanto, não se reduz ao campo do indivíduo, mas pertence de modo integral a todo o processo de "produção social e material" (Guattari, 1996, p. 32) da existência. Tratando desse assunto, saindo então do plano individual, o filósofo propõe uma "economia coletiva" (Guattari, 1996, p. 33) composta por "agenciamentos coletivos" (idem) da subjetividade, os 
quais, por vezes, se materializam também no campo do individual. Dessa forma então, podemos compreender que a subjetividade é essencialmente social e está em circulação, os indivíduos apenas a assumem concretamente em momentos de existência singular. Essa recepção pode ser de dois modos: o da alienação e da opressão, modo de subjetivação que vem de cima, chega ao sujeito e o esmaga, em uma relação de repetição; ou então, pode ser criativa, na qual o sujeito se apropria dos modos de subjetividade e busca transformá-los, transformando-se também.

A subjetividade é esmiuçada em vários componentes, cada qual de uma ordem diversa. Para Guattari, alguns desses elementos seriam de ordem inconsciente, outros da ordem do corpo, outros da ordem dos grupos nos quais se inserem as pessoas, alguns ainda seriam da ordem da produção de poder, como a lei, a polícia etc. Ele vai além e afirma que haveria uma subjetividade maior, de ordem capitalística. O indivíduo, dessa forma, se posicionaria na encruzilhada desses componentes da subjetividade. E a sociedade, por sua vez, não seria o aglomerado de subjetividades individuais, mas é a subjetividade individual que é atravessada por agenciamentos coletivos diferentes (econômicos, culturais, midiáticos etc.).

Com a Revolução Francesa, não só todos os indivíduos tornaram-se de direito - e não de fato - livres, iguais e irmãos (e, além disso, perderam suas aderências subjetivas aos sistemas de clãs de grupos primários), mas também tiveram de prestar contas a leis transcendentais, leis da subjetividade capitalística. Nessas condições, foi necessário fundar, em outras bases, o sujeito e suas relações: a relação do sujeito com o pensamento (o cogito cartesiano), a relação do sujeito com a lei moral (o numen kantiano), a relação do sujeito com a natureza (outro sentimento em relação a natureza e outra concepção de natureza), a relação com o outro (a concepção do outro como objeto). É nessa deriva geral dos modos territorializados da subjetividade que se desenvolveram não só teorias psicológicas referentes as faculdades da alma, como também uma reescrita permanente dos procedimentos de subjetivação no campo geral das transformações sociais (Guattari, 1996, p. 36).

Retomando a questão da individualidade, podemos perceber que somos cercados por processos de individuação, os quais estão funcionam de modo predominante em prol do controle que o sistema capitalista exerce sobre os homens, e que tais processos são numerosos. De acordo com Guattari (1996), o primeiro deles advém do fato de que o homem é um ser biológico, comprometido com a própria sobrevivência. A divisão sexual também é um nível de individuação: homens, mulheres, homossexuais etc. Há também as classes econômicas: classe a, classe b etc., pobres, ricos, classe média. Somos, por meio desses processos, perfeitamente referenciáveis a certas marcas identitárias. A individuação, portanto, abarca a integração e as práticas de normalização. A tendência social é de individuar a subjetividade, de responsabilizar a subjetividade pelas ações dos indivíduos. Isso gera uma série de processos como a repressão e a culpabilização.

Tendem a querer relacionar a subjetividade a uma identidade individual, considerando que os conjuntos familiares e sociais seriam como superestruturas em relação à subjetividade individuada. A meu ver, isso está na base de todas as visões redutoras no campo da fenomenologia e da psicologia. No entanto, os comportamentos, os engajamentos nos sistemas de valor jamais provêm dessa individuação (Guattari, 1996, p. 37).

De acordo com Guattari (1996), o Capitalismo Mundial Integrado (CMI), partindo da lógica apresentada, oprime de vários modos: por meio da opressão socioeconômica, pela manutenção hegemônica do poder nas mãos de determinados grupos, pelo controle da produção de bens de consumo e também por meio da oferta de conteúdos de significação, de sentidos para a vida. Outra forma importante de opressão seria a da produção de subjetividade serializada, nivelada a favor de lógica de mercado.

A produção de subjetividade pelo CMI é serializada, normalizada, centralizada em torno de uma imagem, de um consenso subjetivo referido e sobrecodificado por uma lei transcendental. Esse esquadrinhamento da subjetividade é o que permite que ela se propague, no nível da produção e do consumo das relações sociais, em todos os meios (intelectual, agrário, fabril, etc.) e em todos os pontos do planeta (Guattari, 1996, p. 40).

Em sua discussão, o autor vai tratar ainda sobre alguns mecanismos e funções do que ele chama de 
"economia subjetiva capitalística" (Guattari, 1996, p. 41). O primeiro é a culpabilização:

A culpabilização é uma função da subjetividade capitalística. A raiz das tecnologias capitalísticas de culpabilização consiste em propor sempre uma imagem de referência a partir da qual colocam-se questões tais como: "Quem é você?", "você que ousa ter uma opinião, você fala em nome de quê?", "o que você vale na escala de valores reconhecidos enquanto tais na sociedade?", "a que corresponde sua fala?", "que etiqueta poderia classificar você?" (Guattari, 1996, p. 40).

Entretanto, essa exigência de que o indivíduo seja codificado por meio de um posicionamento identitário fixo não se realiza sozinha, o indivíduo precisa ser envolvido e processado por um conjunto de agenciamentos coletivos. Por exemplo, uma instituição totalitária que aliena o sujeito, não permitindo seu contato com a diferença, dificulta esse acesso aos agenciamentos, e $\mathrm{o}$ indivíduo vacila frente à exigência de uma imagem de referência, permitindo que, de alguma forma, o eu do indivíduo se desestruture. "É como se o próprio direito de existência desabasse" (Guattari, 1996, p. 41). Isso, segundo o filósofo, faz com que o indivíduo se cale e internalize os valores oferecidos inclusive, impostos a ele. Outro mecanismo é a segregação, que cria uma espécie de "hierarquia inconsciente, sistemas de escala de valor, e sistemas de disciplinarização" (Guattari, 1996, p. 41) que são parte dessa ordem social segregadora e consolidam uma certa consistência subjetiva à elite, criando uma divisão social na qual os indivíduos devem se enquadrar. Podemos destacar também, como mais um mecanismo, a infantilização. Nela, tudo que se pode fazer é controlado e qualificado ou desqualificado pela autoridade. Pensam, escrevem, criam pelo sujeito. O Estado, por exemplo, media vários setores importantíssimos da vida da população e do indivíduo, que seriam, supostamente, promotores de autonomia. Vale ressaltar que a subjetividade capitalística se forma tanto do lado daquele que oprime como do lado do que é oprimido: as pessoas subjulgadas ao poder tendem a criar uma relação de dependência e a se apaixonarem por ele, a entenderem que o querem a partir desse lugar de subordinação (Guattari, 1996, p. 44). Uma vez esclarecidos o lugar teórico e técnico da investigação proposta, passamos a apresentar uma resenha da bibliografia que nos permitiu conhecer melhor a RCC e seus mecanismos institucionais.

\section{Aspectos da religiosidade carismática na literatura}

Silva (2011), pesquisador da religião, analisa a religiosidade carismática no artigo "Renovação Carismática Católica: campo de convergência entre fé (milagres) e razão (medicina formal) na atualidade". Afirma que esse tipo de religiosidade é marcado pela tentativa de dar sentido a certo contexto conflitivo dos sujeitos. Geertz (1989 apud Silva, 2011), estudado por Silva, afirma que os símbolos religiosos variam muito, de acordo com a necessidade e contexto sociais, e dão novo sentido ao objeto real. $O$ pesquisador toma ainda a posição de Berger (1985 apud Silva, 2011), e afirma que a religião é essencialmente "nomisante", porque protege os fiéis do risco de uma vida sem sentido, de um estado de anomia. Silva (2011) demonstra que ela se constitui como uma força terapêutica, ao reordenar o indivíduo em situações de caos social, de perda de sentido e plausibilidade de sua vida. Ele demonstra que, na RCC, a crença na cura por meio de milagres é um ponto central, que influencia, portanto, na posição deste movimento quanto à questão da fé/razão. O pesquisador afirma: "um milagre é um evento fora do comum ou extraordinário que é, a princípio, perceptível pelos outros, que não encontra nenhuma explicação razoável nas habilidades comuns humanas ou em outras forças conhecidas que operam no mundo do tempo e espaço" (Silva, 2011, pp. 191-192). O milagre passa a ser, nessa nova configuração da religiosidade, uma resposta a pedidos pessoais, às dificuldades do fiel, especialmente no sentido da cura de doenças. Especificamente na RCC, valoriza-se muito a questão da saúde dos fiéis, como um dos sinais da benção divina. O milagre está em prol da cura; isso é devido ao fato de que o Espírito Santo precisa habitar um corpo saudável, por isso é preciso cuidar dele (pois o corpo é o "templo do Espírito Santo"). Dessa forma, o corpo do fiel se torna também um campo de batalha entre o bem e o mal, entre a saúde e a doença, entre a moral cristã e a moral secular.

Uma característica marcante da RCC é seu caráter mágico, de experiências "transcendentais", como as experiências com os "dons do espírito" que seriam vivenciadas por seus fiéis. Valle (2004) comenta que esse fator é determinante do sucesso ou do repúdio a RCC. Ao mesmo 
tempo em que atrai muita gente, a RCC também é alvo de duras críticas. O mesmo autor afirma ainda que essa característica não seria algo novo: em todas as fases do cristianismo, desde suas primeiras comunidades, até a Idade Média aconteceram fenômenos religiosos com essas mesmas características (Valle, 2004, p. 97). Entretanto, Valle (2004) deixa claro que, apesar de algo comum, o fenômeno do pentecostalismo católico (que é como ele denomina a RCC) é algo singular, que ainda não está entendido de modo completo e merece que se debruce sobre ele. Valle (2004) afirma que, partindo da análise de uma série de estudos acerca do tema, existe uma clara divergência dentro da Igreja Católica, quanto a questões teológicas relacionadas com a RCC. Situações de conflito também existem pela característica de entusiasmo com que os membros defendem os ideais do grupo. Os principais embates, segundo Valle (2004), são entre a RCC e as Comunidades Eclesiais de Base (CEB), derivadas de um catolicismo pautado na Teologia da Libertação. "Poder-se-ia dizer que a RCC é a principal representante de um segmento que tenta levar a Igreja Católica a assumir um caráter mais intimista e pietista que social, negligenciando seu papel na sociedade" (Valle, 2004, p. 98). Além dessa característica, a supremacia da instalação da espiritualidade carismática, para o autor, pode resultar em proselitismo e em uma postura antiecumênica na hora de evangelizar.

Uma interessante tese é apresentada por Valle (2004): assim como a sociedade brasileira, reservando suas singularidades, se pauta e é atravessada pelo american way of life, desde a moda, os celulares, os vários costumes, a atenção à bolsa de valores, o modo de viver a religiosidade também não escapam da hegemonia estadunidense. O modo com que o cristianismo se instala e se modifica lá, de alguma maneira ou de outra, chega no Brasil. Valle (2004) afirma que essa invasão é mais clara no cristianismo pentecostal (do qual a RCC faz parte), do que nas demais igrejas cristãs históricas. Deste modo, a inserção da RCC no catolicismo representa a inserção de um modo de ser americanizado, no interior de uma religião que sempre se pautou pelo modelo europeu e por seu modo de vida. E de fato, foi em uma universidade dos Estados Unidos de América que a RCC teve origem. "Ora, a RCC é um lídimo produto norte-americano. Tem progenitores ianques pelos seus dois lados, pelo do pai (o pentecostalismo) e pelo da mãe (o catolicismo americano em busca de novas vias de expressão)" (Valle, 2004, p. 99). As resistências à RCC se dão pela característica europeia da Igreja no Brasil, bem como pelo "impulso de autoconsciência que o Vaticano II despertou no catolicismo latino-americano" (Valle, 2004, p. 99). O autor comenta que foi na busca por uma nova forma de expressão do catolicismo norte-americano, que estava em crise devido ao influxo do Vaticano II, que surgiu no meio universitário essa forma de pentecostalismo católico. A RCC, como movimento pentecostal, influenciada por uma tradição protestante norte-americana, bem como alguns de seus fundadores tem passagem pelos "Cursilhos de Cristandade". É interessante ressaltar esta última característica, que não encontramos em nenhum outro estudo, porque ela vai influenciar no modo de funcionamento atual do movimento: estes Cursilhos, dos quais alguns dos fundadores da RCC participavam, constituem um movimento religioso católico tradicional, de origem espanhola, rígido, e que criaram e utilizam "técnicas fortes que mexem com o emocional do grupo e desestabilizam os arranjos psicorreligiosos do cotidiano das pessoas" (Valle, 2004, p. 100). Vale ressaltar este aspecto, já que a RCC se revela nesta pesquisa, como um movimento que utiliza principalmente deste tipo de técnicas no seu processo de produção de subjetividades. Valle (2004) resume muito bem o caminho/estratégia que pode ser traçado nesta produção.

(...) reestruturação do campo perceptivo e da autocompreensão do sujeito tem suporte nos fervorosos grupos de oração que a RCC incentiva com o objetivo de manter vivo o primeiro entusiasmo dos membros. Há também atividades de formação especialmente as relativas à Bíblia, em uma linha quase sempre fundamentalista. Simultaneamente, a RCC orienta os novos adeptos para uma ação evangelizadora direta, centrada no testemunho pessoal e grupal coordenado com manifestações massivas de evangelização (...) (Valle, 2004, p. 102).

Na história da Igreja Católica, sempre houve movimentos externos e internos, e sua reação frente a eles foi variada. Geralmente, segundo Ribeiro (2011), a Igreja reage negativamente a movimentos que ameaçam seu reinado católico ou a figura soberana do Papa. Esta instituição reinou soberanamente, sobretudo no mundo ocidental, mas perdeu força com as transformações sociais. Com as mudanças na sociedade moderna, a Igreja também se viu impelida a realizar transformações para não ficar relegada à 
margem da histórica contemporânea. Nessa tentativa de mudança, foi realizado o Concílio Vaticano II. Segundo Ribeiro (2011) este momento foi uma tentativa da Igreja Católica de se contextualizar no mundo, saindo de uma longa fase de conservadorismo. Ele ainda comenta que este Concílio promoveu diversas mudanças na liturgia e na abertura ecumênica, bem como deflagrou o surgimento de diversos movimentos religiosos no interior da Igreja Católica, marcados pelos mais variados tipos de orientação teologia, ética e política. Dentre eles, um que encontrou terra fértil para se estabelecer foi a RCC.

A RCC, segundo Ribeiro (2011), é o movimento que mais cresce desde então. Ele a divide em três momentos, os quais o autor chama de três "ondas". Afirma que a RCC se fixou cada vez mais na Igreja Católica em contraponto com as CEBs. A principal diferença entre os dois movimentos é que a RCC, segundo Ribeiro (2011, p. 174) age de forma vertical, se pauta numa espiritualidade de matiz "íntimo" individualista, com leituras fundamentalistas da Bíblia que proporcionam uma moral acentuada no controle do corpo, da sexualidade e na tradição familiar. Podemos destacar também seu caráter despolitizado, sem crítica. Em contrapartida, as CEBs se caracterizariam por ações horizontais, politizadas, e por leituras críticas da Bíblia, não fomentando atitudes e comportamentos fundamentalistas. De acordo com o autor, a RCC ganha cada vez mais espaço por utilizar de uma estratégia de aderir e adaptar-se às estruturas eclesiásticas, sem questionamentos quanto à autoridade do clero, enquanto movimentos como as CEBs, por agirem de modo crítico, são cada vez mais abafados no contexto eclesial. Outro fator importante ao qual Ribeiro (2011) dá ênfase, e que encontramos em todos os outros autores que estudam a RCC, é sua raiz e semelhança com o pentecostalismo, mas, ao mesmo tempo, sua constante busca em se diferenciar dele. Apesar das diferenças, é nesse tipo de religiosidade que o movimento da RCC buscou as estratégias utilizadas para manutenção da adesão de fiéis. Como exemplos de práticas comuns, podemos destacar a utilização dos dons do Espírito, da cura, da glossolalia, além da prática constante de exorcismo de demônios (Ribeiro, 2011, p. 175), algo que praticamente não se verifica em outros tipos de movimentos religiosos no contexto católico. Sintetizando, as três ondas do movimento da RCC, seriam as seguintes: 1) etapa fundacional, 2) proliferação de padres e leigos cantores e 3) neopentecostalização católica (Carranza,
2009, p. 33-34 apud Ribeiro, 2011, p. 176). Vamos explicitar cada uma delas a seguir.

Em relação à primeira onda, Ribeiro (2011) comenta sobre a fundação do movimento por estudantes universitários norte-americanos, em 1967. Depois de uma experiência com os “dons" do Espírito, tais estudantes passaram a buscar uma vida pautada nestes dons e fundaram o que hoje se conhece como a RCC. Ela chegou ao Brasil por meio de dois padres jesuítas, Haroldo Rahm e Eduardo Dougherty (Ribeiro, 2011, p. 177), em Campinas/SP e depois se espalhou pelo país. Concomitante ao seu crescimento, ocorreu sua estruturação institucional e sua "burocratização e rotinização do carisma" (Ribeiro, 2011, p. 177). Foi nessa fase que se começou a instituir o funcionamento dos grupos de oração, bem como os retiros semanais, mensais, semestrais e anuais por meio dos quais a RCC forma seus membros. Sobre a segunda onda, Ribeiro (2011) comenta que se constituiu como a fase em que a RCC se estabeleceu social e culturalmente, utilizando do lazer e da música como estratégias de conquista para indivíduos afastados, buscando conquistá-los como fiéis e participantes do movimento. Segundo o autor, essa onda da RCC mobilizou milhões de pessoas no Brasil. Além disso, ao analisar os motivos que levam um indivíduo a buscar a RCC, indica que quase sempre estão ligados ao plano emocional da experiência religiosa. Ribeiro (2011), ao comentar esta segunda fase, problematiza uma contradição: o motivo de rejeição por boa parte da Igreja Católica aos carismáticos é o mesmo que os mantém dentro dela com "sucesso". E esse motivo seria a herança pentecostal. Ao mesmo tempo em que o alvo das críticas ao movimento é sua imensa semelhança com as "seitas" e igrejas pentecostais, é devido às estratégias herdadas deste grupo que os carismáticos atraem muita gente, e são como que a solução para a perda de fiéis que o catolicismo vinha sofrendo (Ribeiro, 2011, p.179). Dentre essas estratégias, é preciso destacar a forte produção de música e eventos gospels. Quase que em tom de desabafo, Ribeiro (2011) comenta sobre a comercialização da religião, a capitalização da mesma, tendo em vista que a Igreja deu espaço à musicalidade carismática como forma de embate aos cantores protestantes que vendem muito: "os tempos mudaram e a Igreja Católica não poderia ficar atrás nesse concorrido mercado religioso em que a música 'gospel' passou a ser um produto de alto consumo" (Ribeiro, 2011, 
p. 180). Então a RCC se caracteriza como herdeira e ao mesmo tempo escudo contra o crescimento do pentecostalismo protestante.

Sobre a terceira onda, baseado com Carranza (2009 apud Ribeiro, 2011), o autor a denomina como a neopentecostalização do catolicismo. Esta seria uma fase de novos desenvolvimentos da RCC, marcados principalmente pelo crescimento de comunidades com características da performance carismática, as chamadas Novas Comunidades (Ribeiro, 2011, p. 182), que identificamos como as Comunidades deVida, e por sua preferência em utilizar da mídia como forma de expansão. As comunidades são aquelas como a Canção Nova e a Shalom, que possuem casas próprias, um tipo de "carisma" específico (modo de evangelizar), sites, canais e programas de televisão e eventos religiosos próprios e normalmente grandiosos etc., mas que funcionam todos pautados pelo ideário moral da RCC. Estes fatores, segundo Ribeiro (2011), indicam uma tentativa de segmentos da Igreja Católica em utilizar as mesmas estratégias que as igrejas protestantes pentecostais e neopentecostais, na busca por conquistar e manter fiéis. Nessa onda, devido às referidas Comunidades de Vida, uma das características marcantes é que o Brasil se torna como que um "exportador de missionários" (Ribeiro, 2011, p. 183). Em relação à mídia, a análise do autor é de que ao se inserir nesse meio, a RCC fundou o catolicismo midiático, uma versão religiosa da sociedade de consumo, que se "permite" fazer parte desta cultura com fins de evangelização. Ribeiro (2011) conclui que o novo estilo de ser católico, o carismático, faz com que o catolicismo tradicional, não incorporado com as ondas pentecostais e neopentecostais, se torne algo rejeitado por muitos fiéis. A Igreja, segundo ele, por muito tempo postergou sua entrada nos meios "tecnológicos", entrada forçada agora pela RCC. Essa onda carismática se caracteriza então como uma "comporta" para o "escoadouro" (Ribeiro, 2011, p. 185) de fiéis pelo qual vinha passando a Igreja Católica. Fica a questão de que na verdade, a Igreja Católica, com esse novo estilo de discursos e de práticas de fé, passou de uma atitude de contracultura para se tornar mais um produto da sociedade capitalista globalizada.

\section{Discutindo algumas características dos movimentos religiosos totalitários}

Benelli e Costa-Rosa (2006), no artigo "Movimentos religiosos totalitários católicos: efeitos em termos de produção de subjetividade", discorrem sobre um caso singular de um jovem que ingressou em um movimento chamado Focolare, e que, depois anos de adesão e participação, buscou se desvencilhou deste grupo religioso. Por meio deste artigo, com base nas teorias de Goffman (1987), analisam alguns mecanismos principais de captura e produção de subjetividade operados por tal movimento, e expandem a análise para outros movimentos considerados totalitários. Utilizamos este artigo para encontrar as principais características de movimentos totalitários, e verificar se estas existem também no movimento da RCC. Fazemos isso porque, assim como estes autores, pensamos que a análise de um caso singular nos permite uma análise do panorama geral das instituições semelhantes, por considerá-lo não como um caso idiossincrático, mas singular: “[...] um caso é considerável singular na medida em que encerra as informações essenciais sobre as características básicas do fenômeno que procuramos compreender, e sobre os processos que aí estão em ação" (Benelli, \& Costa-Rosa, 2006, p. 340). Dessa forma, um caso singular é representativo de outros fenômenos e jogos de poder que o cercam, e que existem em outras localidades. Mas obviamente não pretendemos estabelecer uma análise que pretende ser universal, posto que cada movimento possui, não só características comuns, mas também sua singularidade.

O primeiro dos elementos detectado pelos autores seria o que se denomina de "rituais de mortificação do eu". Por meio do isolamento da sociedade, e das intensas técnicas pedagógicas por meio de palestras, discursos, discussões, práticas de oração etc., o movimento visa mortificar o eu do indivíduo, buscando obstruir seus modos singulares de existência mais antigos, para implantação do novo modo de vida, proposto pelo movimento. Tais técnicas são permitidas justamente porque, no caso citado, o sujeito é literalmente isolado da sociedade, tanto fisicamente quanto culturalmente. São proibidos livros, música, filmes entre outros elementos "seculares". Os autores afirmam que os movimentos utilizam de técnicas de marketing, de Psicologia social e de massa. Fazem com que o sujeito fique insatisfeito o suficiente com a própria imagem para que possa romper com o "homem velho" e adotar o "homem novo" que o grupo disponibiliza (Benelli, \& Costa-Rosa, 2006). Várias palestras são taticamente preparadas com este fim, e agem sobre o indivíduo que está isolado do social e sem seus modos de defesa habituais. Desta forma, é inculcado nele uma visão extremamente negativa de sua condição de homem, e é reforçada a sua pequenez 
moral. Isso faz com que, automaticamente, o sujeito demande uma mudança: "Então os indivíduos podem ingressar no grupo, aderindo à proposta apresentada, que já estava preparada anteriormente, com recursos e estruturas de apoio" (Benelli, \& Costa-Rosa, 2006, p. 344). Os autores comentam a existência destes

rituais de mortificação do eu e negação da história pregressa (desterritorialização social e subjetiva) e instauração de outra identidade radicalmente diferente da anterior, com características totalitárias; observaremos, ainda, a presença do retorno, nos institucionalizados, de uma série de efeitos subjetivos de natureza sintomática, expressos em performances radical e maciçamente identificatórias, como a atitude fanática (Benelli, \& Costa-Rosa, 2006, p. 341).

Vale ressaltar que tais performances geradas pela identificação dos sujeitos com o padrão institucional seriam diferentes de uma identidade própria. Esta última "supõe um mínimo de identificação e é a base para performances não imitativas, portanto singularizadas" (Benelli, \& Costa-Rosa, 2006, p. 341). Verificamos, a partir da AI, que uma instituição se compõe de forças contrárias, contraditórias, num plano dialético. Tais forças se produzem e se modificam juntas. Portanto, percebemos que nas instituições totalitárias, também podemos encontrar efeitos de poder negativos e positivos: repressão, mortificação do eu, ao mesmo tempo que produção de novas subjetividades. Os autores afirmam ainda que, nesse processo de supressão dos antigos modos de subjetividade, pode ocorrer um tipo de performance que se relaciona com o sintoma, ou seja, há um retorno da singularidade que foi recalcada, sob a forma de sofrimentos variados e "modo de ser estereotipados" (Benelli, \& Costa-Rosa, 2006, p. 341) dentre os quais o fanatismo religioso seria apenas mais um aspecto.

Podemos indicar desde já um exemplo desse retorno do recalcado: nesse tipo de instituição o indivíduo se forma formador; isso implica em que cada um terá que reproduzir em futuros candidatos os processos de que foi objeto. Nesse momento pode surgir uma forma de retorno do recalcado de modo denegatório (Freud, 1925), justamente na forma de comportamentos e ditames radicalmente estereotipados. Tudo se passa como se o indivíduo, agora na posição de formador, pudesse conjurar, através da repetição, na relação com seus formandos, os conflitos e angústias decorrentes do mesmo processo a que fora submetido e que em si mesmo permanecem não equacionados (Benelli, \& Costa-Rosa, 2006, p. 341-342).

Nos movimentos totalitários também ocorre um tipo de fenômeno denominado de "autoridade escalonada” (Benelli, \& Costa-Rosa, 2006, p. 343), que permite que qualquer sujeito detentor de um cargo de poder possa impor disciplina a qualquer um dos outros membros que the estejam subordinados. Além dessa característica, assim como explicitado por Benelli e Costa-Rosa (2006) e por Libânio (2003), há uma clara tendência anti-intelectual nesses movimentos religiosos. Não sabemos se isso necessariamente faz parte integrante de todos movimentos totalitários, mas, tanto no Focolare como na RCC, está presente. Podemos percebê-la no fato de que tais movimentos incentivam os participantes mais críticos à obediência, ao não questionamento da autoridade, à leitura somente da bíblia e de literatura relacionada à religião e sancionadas pelo grupo. Ou seja, é uma tentativa de enquadrar o sujeito no ideal do grupo, de modo que não haja possibilidade de crítica sobre o instituído e de reflexão instituinte e criativa.

Os movimentos totalitários no geral agem na produção de subjetividade por meio de mecanismos de subtração, cortando, podando, separando, distanciando. Entretanto, podemos perceber, nestes movimentos totalitários religiosos, que a produção de subjetividade também é feita por meio de acréscimos, sobretudo, de imaginário. Por meio da oferta de identificações de tipo massa-líder, ocorre a substituição de um modo subjetivo singular para outro coletivo e altamente idealizado. E é esse o elemento que compõe o caráter "voluntário" com que os indivíduos se submetem livremente à instituição (Benelli, \& Costa-Rosa, 2006, p. 345).

Identificamos esta produção de subjetividade como serializada, ou seja, fabricação em série do idêntico, de modo que suprime, ou pretende suprimir, toda singularidade do sujeito. Modos de existência totalmente institucionalizados fazem com que os sujeitos se tornem insípidos, uniformizados. Quando o indivíduo perde sua característica singular, sua existência autônoma, e passa a ter uma existência completamente institucional, vive apenas em função das realizações e 
triunfos da organização. Benelli (2006) demonstra que, apesar de constantemente incentivada, a supressão das singularidades nunca consegue sucesso total, a supressão dos desejos singulares, da sexualidade e das emoções por vezes eclode e demonstra conflitos inconscientes abafados a duras penas. Isso geralmente resulta na manifestação "de sintomas como ansiedade, depressão ou excitação motora excessiva. Efeitos típicos da institucionalização da vida humana costumam ser sintomas de tensão extrema, de estresse, medo e culpa" (Benelli, \& Costa-Rosa, 2006, p. 345). Estes elementos, de acordo com nosso ponto de vista, claramente mantêm de alguma forma, a supremacia da instituição, ao prender o indivíduo em sua fragilidade emocional e culpabilizada.

Retomando a questão do reforço a uma não intelectualidade, uma aversão ao pensamento crítico, parece que os movimentos totalitários, assim como o movimento Focolare analisado no artigo, agem explicitamente sobre o corpo, e por meio de uma ação sobre o corpo que modelam seus sujeitos. Isso de modo que não há de fato uma formação intelectual, mas uma modelagem subjetiva por meio de práticas institucionais diversas:

podemos verificar toda uma "arte das relações de poder” (Foucault, 1999, p. 245) que é aprendida ao mesmo tempo em que se é submetido a ela, sem maiores teorizações. $\mathrm{O}$ corpo mesmo parece ser o objeto da formação/conversão/modelagem ao formato do movimento (Benelli, \& Costa-Rosa, 2006, p. 347).

Dessa discussão, resulta, portanto, que os movimentos neofundamentalistas, nos quais se enquadra tanto o movimento Focolare analisado pelos autores quanto a RCC possuem características comuns ao totalitarismo: utilizam de uma pedagogia eminentemente tradicional, a qual trata os sujeitos que aprendem como objetos nos quais se deve inscrever uma série de conhecimentos verdadeiros que não podem ser questionados. O modo de transmissão do conhecimento é autoritário, de mestre para discípulo. O centro da atividade de formação é o líder, não se trata de uma construção mútua, e este detém todo o saber e todo o poder. O discípulo exemplar é aquele que apenas assimila e reproduz, sem questionar nada. "Autoritarismo social, disciplina rígida, ordem e submissão, imposição de ideias e conceitos, valorização da hierarquia e da tradição parecem caracterizar esses grupos, além dos outros rituais comuns às instituições totais" (Benelli, \& Costa-Rosa, 2006, p. 349).

\section{Atravessamentos institucionais na RCC}

Feitas estas análises acerca dos movimentos religiosos totalitários, pretendemos agora expor alguns fatores que demonstram o atravessamento destes movimentos na RCC. Ou seja, encontramos características de movimentos totalitários no movimento estudado. De acordo com a tese de Sofiati (2009) e com o que pudemos observar nos documentos colecionados e estudados, dentro do movimento há uma intensa luta contra a moral laica circundante. A RCC possui uma ética própria, modeladora das relações de seus participantes com o mundo, com a família etc. Focado nos jovens, os encontros para essa faixa etária tratam sempre dos temas da afetividade e da sexualidade, tomando essas questões como referentes à juventude. Vários eventos festivos "cristãos" são realizados, numa tentativa clara de afastar a juventude da cultura secular.

A RCC se constitui em uma sociedade dentro da sociedade e uma igreja dentro da Igreja, o que poderia ser caracterizado como uma sociedade inclusiva. O que significa que a RCC parece preencher todas as necessidades de seus membros e se auto-abastece, aspirando a ser a totalidade referencial de seus seguidores. De tal forma essa totalidade referencial pode levar o membro da RCC a um encasulamento, isto é, dispondo de todos os serviços que a estrutura lhe oferece ele não precisa sair do movimento para a sociedade. (Carranza, 2000, p. 61 apud Sofiati, 2009, p. 90).

A noção de abandono da vida antiga, abertura para uma vida nova e renovada pelo Espírito e a noção de que Jesus que guia o caminho são os pontos fundamentais que a RCC inculca nos seus adeptos. Dessa forma, a vida de todos os evangelizados seria marcada pelo antes - vida ruim, pecaminosa - e depois - "vida renovada em Cristo". Mas, porque marcamos estes pontos? Para mostrar como o movimento de mortificação do eu, de inserção de uma nova identidade completamente serializada constitui uma prática massiva dentro da RCC. O indivíduo que passa a ser seguidor deste movimento é subjetivado de modo a ser preenchido pelo 
mesmo. Sua rotina é cercada, e desta forma ele se retira do meio social e se fixa dentro da instituição.

Sofiati (2009) afirma que a RCC contribui para a magicização da sociedade e de seu reencantamento com tons místico-religiosos e viés fanatizante. Ela reage a certos elementos da modernidade e vai contra a secularização social. O sociólogo afirma ainda que esse aspecto do movimento cria uma tendência ao enclausuramento, o que resulta na criação das comunidades "missionárias", como, por exemplo, a emissora Canção Nova, com espaço próprio e fechado. Por fazer parte de uma ala conservadora, a RCC atua focada sobre a família, no sentido de moralizar os preceitos modernos. Identificamos também outra característica importante, que é a do enclausuramento, mas de modo peculiar, que se dá por meio das "comunidades de vida e aliança".

\section{Considerações Finais}

Se o capitalismo produz sujeitos disciplinados, autovigilantes, a RCC também o faz e ainda vai um pouco mais além. Soma-se aí uma parcela maior de culpabilidade e autoflagelamento moral, próprias do tipo de subjetividade produzida pelo capitalismo, como descrito por Guattari e Rolnik (1996). No caso da RCC,

\section{Referências}

Baremblitt, G. F. (Org.). (1994). Compêndio de análise institucional e outras correntes: teoria e prática. Rio de Janeiro, RJ: Record.

Benelli, S. J. (2010c). Formação nos seminários: condicionamentos e problemas comuns. Revista Eclesiástica Brasileira, 70(278), 400-422.

Benelli, S. J. (2010a). Percurso institucional do seminarista diocesano rumo ao sacerdócio. Revista de Psicologia da UNESP, 9(2), 1-17. Recuperado de http:/ / 186.217.160.122/revpsico//index.php/revista/article/view/182/232

Benelli, S. J. (2010b). Perfil do presbítero católico: perspectivas divergentes. Revista Eclesiástica Brasileira, 70(279), 580-601.

Benelli, S. J. (2006). Pescadores de homens: estudo psicossocial de um seminário católico. São Paulo, SP: Unesp.

Benelli, S. J., Costa-Rosa, A. (2006). Movimentos religiosos totalitários católicos: efeitos em termos de pro- ela vem em forma da culpa pelos pecados cometidos e a necessidade de redenção frente à vontade divina. Mais que a vigilância sobre si mesmo, típica da sociedade disciplinar, esta, na RCC, é sempre no sentido extremo de conter os exageros, a raiva, a explosão ou o desejo vaidoso e, principalmente, sexual. Os "pecados" relacionados ao uso indevido do corpo são os mais constantemente condenados pelo movimento, tais como se embriagar, usar substâncias tóxicas ilícitas, fazer sexo sem o comprometimento do casamento, a gula etc. Também é condenável, como pudemos observar, atitudes de rebeldia, ou de explosão de emoções negativas. Podemos citar também a infantilização frente ao Pai provedor de graças e a espera por suas dádivas. Essas características também se enquadram em uma produção da sociedade capitalista, ligadas com os processos de culpabilização (Guattari, 1996). Por meio da infantilização, tudo que os sujeitos fazem é controlado. Pensam, escrevem e criam por eles e para eles, mas sem eles, com o argumento de que é a vontade de Deus, e a inspiração do Espírito Santo. Assim, são produzidos sujeitos fanáticos, alienados, esquivos frente ao social, considerado como mundano. São docilizados e transformados em experts em apenas uma coisa: expandir seu "rebanho"; o que fazem com extremo fervor e dedicação.

dução de subjetividade. Estudos de Psicologia, 23(4), 339-358. doi:10.1590/S0103-166X2006000400003

Cardoso Junior, H. R. (2005). Para que serve uma subjetividade? Foucault, tempo e corpo. Psicologia: Reflexão e Crítica, 18(3), 343-349. doi:10.1590/S0102-79722005000300008

Foucault, M. (1984). O uso dos prazeres. Rio de Janeiro: Graal; 1984.

Foucault, M. (1999). Vigiar e punir: nascimento da prisão. Petrópolis, RJ: Vozes.

Goffman, E. (1987). Manicômios, prisões e conventos. São Paulo, SP: Perspectiva.

Guattari, F.; Rolnik, S. (1996). Micropolítica: cartografias do desejo. Petrópolis, RJ: Vozes.

Libânio, J. B. (2003). Olhando para o futuro: prospectivas teológicas e pastorais do Cristianismo na América Latina. São Paulo, SP: Loyola.

Lourau, R. (1996). A análise institucional. Petrópolis, RJ: Vozes. 
Ribeiro, A. L. (2011). Uma tipologia do pentecostalismo católico: a RCC em ondas. Fragmentos de Cultura, 21(4/6), 171-186. doi:10.18224/frag.v21i2.1881

Silva, S. S. (2011). Renovação Carismática Católica: campo de convergência entre fé (milagres) e razão (medicina formal) a atualidade. Fragmentos de Cultura, 21(4/6), 189-207.doi:10.18224/frag.v21i2.1882

Sofiati, F. M. (2009). Religião e juventude: os jovens carismáticos (tese de doutorado). Faculdade de Filosofia, Letras e Ciências Humanas da Universidade de São Paulo, São Paulo.

Valle,E. (2004).ARenovação Carismática Católica:algumas observações. Estudos Avançados, 18(52), 97-107. doi:10.1590/S0103-40142004000300008

Silvio José Benelli

Doutor em Psicologia Social pelo Instituto de Psicologia, USP, São Paulo. Professor assistente doutor no Depto. de Psicologia Clínica e no Programa de Pós-Graduação em Psicologia da FCL/UNESP, Assis, SP. Brasil.

E-mail: benelli@assis.unesp.br
Samuel Iauany Martins Silva

Acadêmico de Psicologia da Faculdade de Ciências e Letras da Universidade Estadual Paulista Júlio de Mesquita Filho, Assis, SP. Brasil.

E-mail: saiauany@gmail.com

Endereço para envio de correspondência:

Faculdade de Ciências e Letras da Universidade Estadual Paulista Júlio de Mesquita Filho - Campus de Assis. Avenida Dom Antonio, 2100. Parque Universitário. CEP 19806-900. Assis, SP. Brasil.

Recebido 21/10/2014

Reformulação 26/04/2015

Aprovado 29/04/2016

Received 10/21/2014

Reformulated 04/26/2015

Approved 04/29/2016

Recibido 21/10/2014

Reformulado 26/04/2015

Aceptado 29/04/2016

Como citar: Benelli, S. J., \& Silva, S. I. M. (2016). Subjetividade na renovação carismática católica: mecanismos de funcionamento e de sua produção. Psicologia: Ciência e Profissão, 36(3): 610-624. doi:10.1590/1982-3703001432014

How to cite: Benelli, S. J., \& Silva, S. I. M. (2016). Subjectivity in the catholic charismatic renovation movement: mechanisms of operation and their production. Psicologia: Ciência e Profissão, 36(3): 610-624. doi:10.1590/1982-3703001432014

Cómo citar: Benelli, S. J., \& Silva, S. I. M. (2016). La subjetividad en la renovación carismática católica: mecanismos de funcionamiento y su producción. Psicologia: Ciência e Profissão, 36(3): 610-624. doi:10.1590/1982-3703001432014 